\title{
Coordinated Development of Beijing-Tianjin-Hebei City Group from the Perspective of Regional Economics - Comparative Analysis Based on the Gravity Model
}

\author{
Yuan Bing ${ }^{1}$ \\ ${ }^{1}$ School of Economics and Management, Beijing Jiaotong University, Beijing, China \\ Email: 18120540@bjtu.edu.cn
}

\begin{abstract}
Promoting the coordinated development of Beijing-Tianjin-Hebei, adjusting the regional economic structure and spatial structure, and promoting the construction of Hebei Xiong'an New District and Beijing's urban subcenters are one of China's three major national strategies. From the perspective of regional economics, this paper quotes a gravity model, and analyzes the strength of the economic connection between the BeijingTianjin-Hebei urban agglomeration and the Yangtze River Delta city agglomeration. The cluster is obviously weaker than the Yangtze River Delta city cluster. To develop the Beijing-Tianjin-Hebei urban agglomeration into a world-class urban agglomeration, it is necessary to take advantage of the opportunity to build the Xiong'an New District, to defuse Beijing's non-capital functions, solve "big city diseases", improve the functions of surrounding cities, and build a good-level, close-knit economic cluster pattern.
\end{abstract}

Keywords: Beijing-Tianjin-Hebei urban agglomeration, economic linkage strength

\section{INTRODUCTION}

Looking at the world urbanization process, urban agglomerations are the main form and space carrier of urbanization development. Since entering the 21st century, the domestic economy has developed rapidly, the level of urbanization has continued to accelerate, and the size of urban agglomerations has gradually expanded. The total area of Beijing, Tianjin and Hebei is 215000 square kilometers, with a GDP of 8.5 trillion yuan in 2018.It is an important economic growth pole in North China, as well as China's ability to participate in economic globalization and improve international exchanges. In April 2017, the CPC Central Committee and the State Council decided to establish xiong'an New Area in Hebei Province. In November 2018, the Central Committee of the Communist Party of China and the State Council clearly requested that the goal is to ease the non capital functions of Beijing, promote the coordinated development of Beijing, Tianjin and Hebei, and adjust the regional economic structure and spatial structure. The construction of world-class urban agglomerations in Beijing, Tianjin and Hebei is conducive to enhancing its influence and driving force on the whole country. This paper will analyze the Beijing Tianjin Hebei Urban Agglomeration and the Yangtze River Delta urban agglomeration from the perspective of regional economics, so as to provide useful reference for Beijing Tianjin Hebei to build a world-class urban agglomeration.

\subsection{Related Work}

According to the research content, this article divides the literature into three categories.

\subsubsection{City group construction}

The formation of world-class urban agglomerations first requires the existence of world-class big cities as the core. For example, in 2012, the 2010 China Urban Agglomeration Development Report stated that the Yangtze River Delta urban agglomeration with Shanghai as its core has ranked among the six world-class urban agglomerations. Beijing's international influence is increasing, and consensus has been reached on building a world-class city [1]. The motivation for Beijing, Tianjin and Hebei to build a world-class urban agglomeration is not only the need to build a new economic growth pole and promote economic development in China, but also the need for coordinated development of Beijing, Tianjin and Hebei and the need to solve urban diseases in the capital [2]. And Chunbin Liu compared the urban agglomeration of Boshua with the Beijing-Tianjin-Hebei urban agglomeration in terms of its macro-status, spatial structure, and carrying capacity , and found that the main problems of Beijing-Tianjin-Hebei city group are the concentration of the bearing function of the city and the disharmony of the urban development relationship[3]. 


\subsubsection{Regional Synergy Development}

Xijun Zhao believes that regional coordinated development is the premise to ensure the stable, healthy and efficient operation of regional economy[4]. The development level and positioning of Hebei Province are far lower than those of Beijing and Tianjin, while many indicators of Tianjin and Beijing are at the same level, The three regions have not formed a good development gradient level. It is difficult for Beijing, Tianjin and Hebei to find common interest demands to promote regional coordinated development in the current position. The cooperation momentum is obviously insufficient, let alone regional integration. Zhang Shuo, Yan Zhao and others believe that regional economic cooperation has become the main means for the continuous improvement of China's market economy system, and will become a new trend and new power for China's future social and economic development. The economic development of Beijing, Tianjin and Hebei shows inconsistent phenomenon, which seriously affects the comprehensive economic development of Beijing-Tianjin-Hebei[5].

\subsubsection{Intensity of economic ties}

The process of regional economic linkage is actually a process of interaction in the economic field. The emergence and development of regional economic links is the result of the division of labor in regions [6]. In order to measure the degree of regional economic linkage, the indicator of the strength of economic linkage has been produced. It reflects both the ability of the economic center to radiate (diffuse and polarize) the surrounding area and the ability of the surrounding area to accept the radiative potential of the economic center [7]. Further, the amount of economic contact is used to measure the strength of the economic connection between regions. It can reflect both the central city's radiation ability to the surrounding area and the degree of acceptance of the central city's radiation ability [8].

\subsection{Our Contribution}

This article will introduce the gravity model to quantify the total amount of economic links and the strength of economic links between different cities in the BeijingTianjin-Hebei region, and compare and analyze with the relevant data of the Yangtze River Delta city group to find out the development of the Beijing-Tianjin-Hebei city group. Problems and make some enlightenments.

\subsection{Paper Structure}

The rest of the paper is arranged as follows. The second section introduces the theoretical model and measurement model used in this paper, and introduces the data source.
The third section is empirical analysis. Finally, the sixth part summarizes the thesis and puts forward the future research direction.

\section{THEORETICALMODELANDECONOMETRIC MODEL}

\subsection{Theoretical model}

It is generally believed that the strength and quantity of interregional economic ties are important indicators to measure the process of regional coordinated development. The essence of the process of interregional economic connection is the process of interaction in the economic field. This is undoubtedly closely related to their economic development level and population scale. Therefore, the level of economic development and population size are important indicators to calculate the strength of regional economic ties. At the same time, according to the theory of distance attenuation[9], the spatial distance between regions is another important index that affects the intensity of regional economic ties. Based on the above analysis, this paper selects regional population, GDP, spatial distance and other indicators to measure the intensity of economic ties between certain regions.

\subsection{Econometric model}

Through the introduction of gravity model[8], we can measure the amount and intensity of economic ties between urban agglomerations. According to the above concept of economic connection quantity and connection strength, 13 major cities in Beijing Tianjin Hebei region and 26 cities in the Yangtze River Delta region are taken as the main objects, and the spatial gravity model is used to calculate the economic connection quantity and connection strength between major cities in Beijing Tianjin Hebei Urban Agglomeration in 2015-2017. The specific formula is as follows:

$$
\begin{gathered}
R_{\mathrm{ij}}=\frac{\sqrt{P_{\mathrm{i}} V_{\mathrm{i}}} * \sqrt{P V_{\mathrm{j}}}}{D_{\mathrm{ij}}^{2}} \\
F_{\mathrm{ij}}=\frac{R_{\mathrm{ij}}}{\sum_{\mathrm{i}=1}^{\mathrm{n}} R_{\mathrm{ij}}}
\end{gathered}
$$

Among them, $R_{\mathrm{ij}}$ represents the economic connection between cities; $P_{\mathrm{i}} 、 V_{\mathrm{i}} 、 P_{\mathrm{j}} 、 V_{\mathrm{j}}$ represents the total urban population and GDP of $\mathrm{I}$ and $\mathrm{j}$ respectively; $F_{\mathrm{ij}}$ represents the economic connection strength between I and j respectively. 
Second, according to the time trend, on the one hand, the economic links between the secondary cities and Beijing and Tianjin are increasing year by year, and the speed of the increase reflects the development speed of the local economic level. On the other hand, the intensity of economic connection between most cities and Beijing is decreasing year by year, which may be conducive to a more reasonable distribution of radiation effect of Beijing. Thirdly, Tianjin, as the core city of Beijing Tianjin Hebei Urban Agglomeration, has not played its role. Beijing is the leader of Beijing Tianjin Hebei Urban Agglomeration, but its position is not the economic center. The existence of this phenomenon will not only squeeze the development of Tianjin, but also is not conducive to the coordinated development of Beijing Tianjin Hebei Urban Agglomeration.

To sum up, the Beijing Tianjin Hebei Urban Agglomeration is more inclined to Beijing single core model, the economic connection between each secondary city and the core city is increasing year by year, indicating that the regional coordinated development is good. However, the connection strength has obvious geographical characteristics, which greatly affects the economic connection quantity and connection strength, which leads to the imbalance of the connection strength distribution of each secondary city, the greater dependence on Beijing, the adverse impact on the development of Tianjin, Shijiazhuang and other large cities, and the coordinated development of the whole city cluster.

Table 3-1 The amount and intensity of economic ties between major cities in Beijing Tianjin Hebei Urban Agglomeration in 2015-2016

\begin{tabular}{|c|c|c|c|c|c|c|c|c|}
\hline \multirow[b]{2}{*}{ Region } & \multicolumn{2}{|c|}{ Beijing（2015） } & \multicolumn{2}{|c|}{ Tianjin（2015） } & \multicolumn{2}{|c|}{ Beijing（2016） } & \multicolumn{2}{|c|}{ Tianjin (2016) } \\
\hline & $\begin{array}{l}\text { Contact } \\
\text { quantity }\end{array}$ & $\begin{array}{l}\text { Contact } \\
\text { strength }\end{array}$ & $\begin{array}{l}\text { Contact } \\
\text { quantity }\end{array}$ & $\begin{array}{l}\text { Contact } \\
\text { strength }\end{array}$ & $\begin{array}{l}\text { Contact } \\
\text { quantity }\end{array}$ & $\begin{array}{l}\text { Contact } \\
\text { strength }\end{array}$ & $\begin{array}{l}\text { Contact } \\
\text { quantity }\end{array}$ & $\begin{array}{l}\text { Contact } \\
\text { strength }\end{array}$ \\
\hline Tianjin & 2184.5947 & $30.8345 \%$ & I & I & 2324.1993 & $30.7918 \%$ & I & I \\
\hline Shijiazhuang & 194.3102 & $2.7426 \%$ & 122.5123 & $4.6818 \%$ & 207.2194 & $2.7453 \%$ & 127.3616 & $4.7032 \%$ \\
\hline Tangshan & 529.3033 & $7.4709 \%$ & 674.2457 & $25.7662 \%$ & 560.5342 & $7.4261 \%$ & 696.0489 & $25.7036 \%$ \\
\hline Qinhuangdao & 57.3651 & $0.8097 \%$ & 44.5819 & $1.7037 \%$ & 63.1931 & $0.8372 \%$ & 47.8745 & $1.7679 \%$ \\
\hline Chengde & 105.7923 & $1.4932 \%$ & 41.2437 & $1.5761 \%$ & 111.5484 & $1.4778 \%$ & 42.3926 & $1.5655 \%$ \\
\hline Zhangjiakou & 160.1821 & $2.2609 \%$ & 39.7965 & $1.5208 \%$ & 165.1021 & $2.1873 \%$ & 39.9860 & $1.4766 \%$ \\
\hline Langfang & 2760.5913 & $38.9645 \%$ & 605.9595 & $23.1567 \%$ & 2967.8541 & $39.3191 \%$ & 635.0502 & $23.4510 \%$ \\
\hline Baoding & 584.8106 & $8.2543 \%$ & 332.7580 & $12.7163 \%$ & 608.5372 & $8.0621 \%$ & 337.5394 & $12.4646 \%$ \\
\hline Handan & 67.2901 & $0.9498 \%$ & 46.5384 & $1.7785 \%$ & 70.4900 & $0.9339 \%$ & 47.5238 & $1.7550 \%$ \\
\hline Xingtai & 56.2674 & $0.7942 \%$ & 38.8439 & $1.4844 \%$ & 60.4669 & $0.8011 \%$ & 40.6918 & $1.5027 \%$ \\
\hline Hengshui & 81.2352 & $1.1466 \%$ & 65.3219 & $2.4963 \%$ & 87.8899 & $1.1644 \%$ & 68.8934 & $2.5441 \%$ \\
\hline Cangzhou & 303.1534 & $4.2789 \%$ & 604.9777 & $23.1192 \%$ & 321.0820 & $4.2538 \%$ & 624.6215 & $23.0659 \%$ \\
\hline
\end{tabular}

\subsection{An analysis of the quantity and intensity of economic ties in the Yangtze River Delta Urban Agglomerations}

According to the $<2016$ national development and Reform Commission's Yangtze River Delta Urban Agglomerations development plan>, the cities under its jurisdiction include Shanghai, Suzhou,and other 26 cities. Shanghai is one of the worthy core cities. In addition, because the distance between Suzhou and Shanghai is the same as that between Tianjin and Beijing, the total GDP of Suzhou is the same as that of Tianjin. As a comparison with the urban agglomeration of Beijing, Tianjin and Hebei, Suzhou is selected as the second core city, and other cities are secondary cities.

This paper selects the relevant data of cities in the Yangtze River Delta Based on the ESP data platform from 2015 to 2017. The calculation results are as follows (Table 3-2): 
Table 3-2 The amount and intensity of economic ties among major cities in the Yangtze River Delta in 2016-2017

\begin{tabular}{|c|c|c|c|c|c|c|c|c|}
\hline \multirow[b]{2}{*}{ Region } & \multicolumn{2}{|c|}{ Shanghai(2016) } & \multicolumn{2}{|c|}{ Suzhou(2016) } & \multicolumn{2}{|c|}{ Shanghai(2017) } & \multicolumn{2}{|c|}{ Suzhou(2017) } \\
\hline & $\begin{array}{l}\text { Contact } \\
\text { quantity }\end{array}$ & $\begin{array}{l}\text { Contact } \\
\text { strength }\end{array}$ & $\begin{array}{l}\text { Contact } \\
\text { quantity }\end{array}$ & $\begin{array}{l}\text { Contact } \\
\text { strength }\end{array}$ & $\begin{array}{l}\text { Contact } \\
\text { quantity }\end{array}$ & $\begin{array}{l}\text { Contact } \\
\text { strength }\end{array}$ & $\begin{array}{l}\text { Contact } \\
\text { quantity }\end{array}$ & $\begin{array}{l}\text { Contact } \\
\text { strength }\end{array}$ \\
\hline Shanghai & I & l & 3305.5327 & $24.1334 \%$ & I & I & 3635.8468 & $23.9197 \%$ \\
\hline Suzhou & 3305.5327 & $32.1732 \%$ & I & I & 3635.8468 & $31.9909 \%$ & I & I \\
\hline Nanjing & 274.2018 & $2.6688 \%$ & 262.0851 & $1.9135 \%$ & 302.1508 & $2.6585 \%$ & 289.7003 & $1.9059 \%$ \\
\hline Wuxi & 1161.7380 & $11.3073 \%$ & 5682.5886 & $41.4880 \%$ & 1289.6351 & $11.3472 \%$ & 6327.8763 & $41.6302 \%$ \\
\hline Changzhou & 444.9924 & $4.3312 \%$ & 790.3193 & $5.7700 \%$ & 495.0108 & $4.3555 \%$ & 881.8966 & $5.8019 \%$ \\
\hline Nantong & 1149.5115 & $11.1883 \%$ & 847.9651 & $6.1909 \%$ & 1276.0608 & $11.2277 \%$ & 944.2546 & $6.2121 \%$ \\
\hline Yancheng & 158.8743 & $1.5463 \%$ & 111.6833 & $0.8154 \%$ & 174.3369 & $1.5339 \%$ & 122.9355 & $0.8088 \%$ \\
\hline Yangzhou & 147.0212 & $1.4310 \%$ & 146.8402 & $1.0721 \%$ & 163.3376 & $1.4372 \%$ & 163.6456 & $1.0766 \%$ \\
\hline Zhenjiang & 146.6900 & $1.4278 \%$ & 163.4023 & $1.1930 \%$ & 155.8842 & $1.3716 \%$ & 174.1858 & $1.1459 \%$ \\
\hline Taizhou & 210.3196 & $2.0471 \%$ & 171.2403 & $1.2502 \%$ & 235.0895 & $2.0685 \%$ & 192.0050 & $1.2632 \%$ \\
\hline Hangzhou & 750.8364 & $7.3080 \%$ & 453.1309 & $3.3083 \%$ & 839.8534 & $7.3897 \%$ & 508.4345 & $3.3449 \%$ \\
\hline Ningbo & 359.2128 & $3.4963 \%$ & 167.5570 & $1.2233 \%$ & 402.4026 & $3.5406 \%$ & 188.2889 & $1.2387 \%$ \\
\hline Jiaxing & 980.4391 & $9.5427 \%$ & 727.5855 & $5.3120 \%$ & 1099.9726 & $9.6784 \%$ & 818.8388 & $5.3870 \%$ \\
\hline Huzhou & 283.5491 & $2.7598 \%$ & 281.4694 & $2.0550 \%$ & 309.8850 & $2.7266 \%$ & 308.5721 & $2.0301 \%$ \\
\hline Shaoxing & 310.2018 & $3.0192 \%$ & 184.0247 & $1.3435 \%$ & 335.2268 & $2.9496 \%$ & 199.4911 & $1.3124 \%$ \\
\hline Zhoushan & 34.5263 & $0.3360 \%$ & 16.3520 & $0.1194 \%$ & 35.8075 & $0.3151 \%$ & 17.0117 & $0.1119 \%$ \\
\hline Taizhou & 88.3485 & $0.8599 \%$ & 48.3160 & $0.3528 \%$ & 98.4245 & $0.8660 \%$ & 53.9944 & $0.3552 \%$ \\
\hline Jinhua & 100.8352 & $0.9814 \%$ & 55.8061 & $0.4074 \%$ & 108.3972 & $0.9538 \%$ & 60.1784 & $0.3959 \%$ \\
\hline Hefei & 81.1296 & $0.7896 \%$ & 60.0575 & $0.4385 \%$ & 90.5433 & $0.7967 \%$ & 67.2353 & $0.4423 \%$ \\
\hline Chuzhou & 49.9891 & $0.4866 \%$ & 41.8864 & $0.3058 \%$ & 55.5950 & $0.4892 \%$ & 46.7290 & $0.3074 \%$ \\
\hline Maanshan & 44.9227 & $0.4372 \%$ & 40.1984 & $0.2935 \%$ & 50.3316 & $0.4429 \%$ & 45.1790 & $0.2972 \%$ \\
\hline Wuhu & 67.9640 & $0.6615 \%$ & 57.9934 & $0.4234 \%$ & 74.5713 & $0.6561 \%$ & 63.8300 & $0.4199 \%$ \\
\hline Xuancheng & 55.6443 & $0.5416 \%$ & 38.9441 & $0.2843 \%$ & 61.6898 & $0.5428 \%$ & 43.3098 & $0.2849 \%$ \\
\hline Tongling & 22.4853 & $0.2189 \%$ & 14.3473 & $0.1047 \%$ & 25.5109 & $0.2245 \%$ & 16.3286 & $0.1074 \%$ \\
\hline Chizhou & 13.6190 & $0.1326 \%$ & 8.4520 & $0.0617 \%$ & 14.6825 & $0.1292 \%$ & 9.1404 & $0.0601 \%$ \\
\hline Anqing & 31.6103 & $0.3077 \%$ & 19.1575 & $0.1399 \%$ & 35.0142 & $0.3081 \%$ & 21.2867 & $0.1400 \%$ \\
\hline
\end{tabular}

It is found that the following phenomena exist:

First, geographical factors still have a great influence on the amount of economic ties between cities, but not absolutely, which shows that the leading role of core cities in the Yangtze River Delta is not only dependent on geographical factors, which will be more conducive to coordinated development.

Second, the secondary core cities have played a significant role in promoting the overall development of regional urban agglomerations. Take Suzhou as an example. There are four secondary cities that have more connections with Suzhou than Shanghai, including Wuxi, which is very close to Shanghai. Its economic connection with Suzhou is five times that of Shanghai.

Thirdly, from the perspective of time, the amount of economic ties between secondary cities and Shanghai is increasing, and the standard deviation of ties is gradually narrowing, which shows that the overall economic level of Shanghai is improving and the development trend is reasonable.

\subsection{A comparative analysis of the empirical results of Beijing Tianjin Hebei Urban Agglomeration and Yangtze River Delta Urban Agglomeration}

Through the introduction of gravity model, the empirical analysis results of the collected data of Beijing Tianjin Hebei Urban Agglomeration and the Yangtze River Delta urban agglomeration are as follows:

Echelon structure: according to the data in 2017, after removing the influence of extreme values, the average value of the difference between the secondary cities of Beijing Tianjin Hebei Urban Agglomeration and Tianjin and Beijing is 54.07, and that of the Yangtze River Delta urban agglomeration is 39.61 , which shows that compared with the Yangtze River Delta, the leading role of other core cities of Beijing Tianjin Hebei Urban Agglomeration is not significant, and the secondary cities are more dependent on Beijing, The echelon structure is weaker 
will flow in continuously. The results of gravity model analysis show that the influence of geographical factors on the strength of the connection is the largest. Therefore, the primary driving force is to cultivate more new core cities and form a relatively perfect urban development echelon structure, so that the marginal income obtained in Beijing is basically the same as that obtained in other core cities, and the unidirectional flow of elements can stop.

Second, speed up the construction of xiong'an new area. In 2017, xiong'an new area was established to ease the non capital function of Beijing, which has a huge role in promoting the coordinated development of Beijing Tianjin Hebei Urban Agglomeration and is the key to the coordinated development of Beijing Tianjin Hebei Urban Agglomeration.

\section{CONCLUSION AND ENLIGHTENMENT}

\subsection{Conclusion}

By introducing gravity model, this paper makes quantitative and comparative analysis on the quantity and intensity of economic ties between Beijing Tianjin Hebei Urban Agglomeration and Yangtze River Delta urban agglomeration:

First, although the overall economic volume of Beijing Tianjin Hebei Urban Agglomeration is large and developing rapidly, there is still a certain gap with the world-class urban agglomeration;

Second, compared with the Yangtze River Delta urban agglomeration, Beijing's single core polarization effect is obvious. The surrounding cities are far less dependent on Tianjin and other core cities than Beijing. Beijing's non capital burden is increased, and other core city functions have not been brought into play. This abnormal echelon structure is not conducive to the internal coordinated development of Beijing Tianjin Hebei Urban Agglomeration.

Thirdly, from the perspective of time span, the gap between the secondary cities and Tianjin and Beijing has been decreasing year by year, which means that the internal structure of the development of Beijing Tianjin Hebei Urban Agglomeration is optimizing, and the overall situation is better. But some cities are more and more dependent on Beijing and occupy the development of other secondary cities, which is not conducive to the growth of other core cities.

\subsection{Enlightenment}

According to the questions raised in the conclusion, the following enlightenment is put forward:

First, speed up the development of Tianjin, Shijiazhuang and other major cities. The root of the problem of Beijing Tianjin Hebei Urban Agglomeration is Beijing's regional strong position, because the essence of factor profitseeking makes as long as the benefit space obtained in Beijing is higher than the surrounding areas, the factors

\section{REFERENCES}

[1] Duan Xia, Wen Kui.Research on the World City Index System Based on Panoramic Observation [J] .Journal of Renmin University of China, 2011,25 (02): 61-71.

[2] Junkuo Zhang. Promote the coordinated development of Beijing, Tianjin, and Hebei to build a world-class city group [J] .Smart China, 2015 (02): 1316.

[3] Chunbin Liu, Zhang Chen.A Comparative Study of Boshua City Group and Beijing-Tianjin-Hebei City Group [J] .City Watch, 2009 (01): 63-69.

[4] Xijun Zhao.Scaling Political Analysis and Path Research on the Coordinated Development of BeijingTianjin-Hebei Region [J] .China Market, 2019 (15): 1-5.

[5] Zhang Shuo, Yan Zhao.Research on Regional Interaction and Coordinated Development of Beijing, Tianjin and Hebei Economy [J] .Cooperative Economy and Science and Technology, 2019 (07): 26-27 .

[6] Lihua Wei.Comparison of Intrinsic Factors for the Coordinated Development of Urban Agglomerations: Beijing-Tianjin-Hebei and the Yangtze River Delta [J] .Reform, 2017 (07): 86-96.

[7] Dezhong Wang, Renxing Zhuang.A Preliminary Study on Quantitative Analysis of Regional Economic Relations-Taking the Economic Relations between Shanghai and Suxichang as an Example [J] .Geographical Science, 1996 (01): 51-57.

[8] Jiuwen Sun, Hongjun Ding.Research on the Process of Regional Economic Integration in Beijing, Tianjin and Hebei $[\mathrm{J}]$.Economic and Management Research, 2012 (07): 52-58.

[9]Wuyang Yang, Principle of Location Theory, Gansu people's publishing house, 1989. 